\title{
Fecal contamination of drinking water in arsenic-affected area of rural Bihar: tube-well and storage container survey
}

\author{
M. Annaduzzaman, L.C. Rietveld \& D. van Halem \\ Sanitary Engineering Section, Faculty of Civil Engineering and Geoscience, Delft University of Technology, \\ Delft, The Netherlands
}

\begin{abstract}
The study aimed to investigate the fecal contamination in shallow (depth $<50 \mathrm{~m}$ ) drinking water tube-wells (TWs) and household storage containers in the arsenic-affected area of rural Bihar. In this study, 365 TWs surveyed for As contamination, 164 TWs, and 68 storage containers for the presence/absence of fecal contamination. The results reveal that $32 \%(n=111)$ of surveyed TWs $(n=365)$ exceeded WHO guideline value for As of $10 \mu \mathrm{g} \mathrm{L}^{-1}$ and $11 \%(\mathrm{n}=40)$ of $50 \mu \mathrm{g} \mathrm{L}^{-1}$. Within $164 \mathrm{TWs}$ and 68 storage containers, $25 \%$ $(n=40)$ and $43 \%(n=29)$ respectively showed presence of fecal contamination. Arsenic contamination did not show significant relation to TWs depth, but deeper $(18-50 \mathrm{~m})$ TWs confirm the presence of fecal contamination. Results also depict that fecal contamination both in source and storage container influenced by socio-economic, sanitation practices, the presence of latrine, livestock close to source or containers.
\end{abstract}

\section{INTRODUCTION}

In Bihar and neighboring areas of large GangesBrahmaputra-Meghna (GBM) Delta, drinking water interventions have much focused on arsenic (As) contamination in shallow groundwater tube-wells installed in millions of households. However, these shallow sandy aquifers are also vulnerable to fecal contamination (Embrey \& Runkle, 2006). In addition, As mitigation technologies might lead exposure to harmful microorganisms ((Leber et al., 2011), as well as improper water storage practices at the household level. Fecal (re)contamination of drinking water may result in transmittance of pathogenic microorganisms leading to an outbreak of diseases including cholera, dysentery, diarrhea, hepatitis, miscarriage and even cryptosporidiosis.

The aim of this research project is to develop a holistic approach towards arsenic mitigation, without increasing the exposure to fecal contamination. In this research, a first step is taken by investigating the state of exposure to fecal contamination via TWs and storage containers in the arsenic-affected areas in Bihar, India.

\section{MATERIALS AND METHODS}

Seven densely populated and geologically comparable rural villages of Barhara Block in Bhojpur district, Bihar were selected for this study. A total of 365 tube-wells water sampled in April 2017 for As and other trace elements analysis via ICP-MS (at TU Delft). Information of sanitation practices was collected through a systematic questionnaire amongst 164 households, using AKVO FLOW smartphone app (AKVO, 2017). For assessment of fecal contamination, the qualitative (presence/absence) Sumeet $\mathrm{H}_{2} \mathrm{~S}$ test for E. coli was used: $20 \mathrm{~mL}$ water sample was directly collected from 164 tube-wells and 68 household containers for analysis.

\section{RESULTS}

\subsection{Presence of arsenic in tube-well water}

Of the 365 surveyed tube-wells, the As level varied from $<1$ to $400 \mu \mathrm{g} \mathrm{L}^{-1}$. According to WHO guideline value of $10 \mu \mathrm{g} \mathrm{L}^{-1} \mathrm{As}, 69.6 \%$ and $30.4 \%$ TWs was safe and unsafe respectively $-19.4 \%$ were in the As range of $10-50 \mu \mathrm{g} \mathrm{L}^{-1}$. In all villages As contamination was observed to exceed WHO value, with one village with unusually high As concentrations $(\mathrm{G})$. In this village 47 wells exceeded the WHO guideline of $10 \mu \mathrm{gL}^{-1}$ (Fig. 1).

\subsection{Fecal contamination in tube-well water}

Among the surveyed 164 tube-wells water for presence/absence of fecal contamination, $75 \%$ TWs were safe and $25 \%$ TWs were contaminated. Within

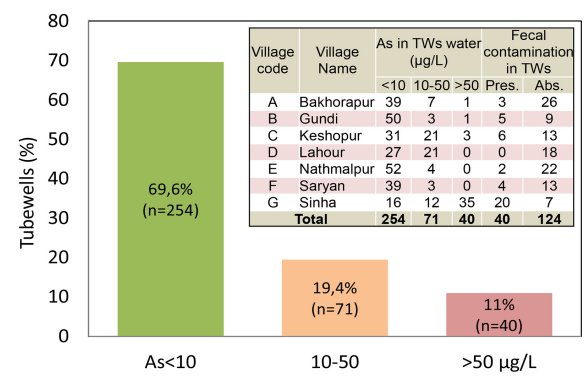

Figure 1. Arsenic distribution in surveyed tube-wells. 
Table 1. Absence or presence of E. coli per sampled TW $(\mathrm{n}=164)$ related to TW characteristics.

\begin{tabular}{lcc}
\hline & \multicolumn{2}{l}{ Fecal contamination } \\
\cline { 2 - 3 } Categories & Absence & Presence \\
\hline Tube-well depth & & \\
$<18 \mathrm{~m}$ & 18 & 12 \\
$18-50 \mathrm{~m}$ & 106 & 28 \\
Toilet distance from TWs & & \\
$<10 \mathrm{~m}$ or NT & 105 & 38 \\
$>10 \mathrm{~m}$ & 19 & 2 \\
TWs distance to livestock & & \\
$<10 \mathrm{~m}$ & 50 & 17 \\
$>10 \mathrm{~m}$ or no LS & 74 & 23 \\
TWs Platform condition & & \\
Good & 59 & 18 \\
Poor/none & 65 & 22 \\
\hline
\end{tabular}

Table 2. Absence or presence of E. coli per water storage practice in 68 sampled households.

Fecal contamination

\begin{tabular}{lrr} 
& Absence & Presence \\
\cline { 3 - 3 } Categories & & \\
Container height from ground & 8 & 21 \\
$<40 \mathrm{~cm}$ & 31 & 8 \\
$>40 \mathrm{~cm}$ & & \\
Light condition to container & 15 & 20 \\
Shadow and cool & 28 & 9 \\
Sunny & & \\
Container clean enough & 19 & 23 \\
Yes & 20 & 6 \\
No & & \\
Container cover & 30 & 8 \\
Yes & 10 & 21 \\
No & & \\
Presence of flies near container & 8 & 24 \\
Yes & 31 & 5 \\
No & & \\
Toilet distance to container & 15 & 25 \\
$<10 \mathrm{~m}$ or NT & 24 & 4 \\
$>10 \mathrm{~m}$ & & \\
Container distance to livestock & 12 & 21 \\
$<10 \mathrm{~m}$ & 27 & 8 \\
$>10 \mathrm{~m}$ or no LS & & \\
\hline
\end{tabular}

the fecal contaminated TWs, it was found that above $70 \%$ TWs were from deep aquifer. In case of presence of toilet (or no toilet at all) within $10 \mathrm{~m}$ of the TWs, in 38 cases found fecal contamination.

The presence of livestock close to TWs $(<10 \mathrm{~m})$ or platform condition (e.g. damaged) did not show a difference in contamination (Table 1).

\subsection{Fecal contamination in storage container}

The presence or absence of fecal contamination in the storage container and the possible pathway are given in Table 2. It was found that, within 68 sampled storage container water, $57 \%$ and $43 \%$ cases were safe and contaminated respectively. Of the households that abstracted microbially safe water from their tube-well, $10 \%(\mathrm{n}=16)$ had contaminated water in the storage container outflow. Vice versa, $5 \%(n=7)$ of the households abstracted contaminated water from their well, but this was not observed in their container.

Table 2 provides an overview of the water storage practices and their corresponding absence or presence of $E$. coli. From these results, it may be concluded that presence of a cover and height from ground ( $>40$ $\mathrm{cm}$ ) prevent re-contamination, but also the placement of the container in sunlight. Heating of the water, as well as UV-irradiation, are known to cause a die-off of pathogens (Sommer et al., 1997). Indicators of hygiene practices, like distance to the toilet, livestock, and presence of flies, clearly show more presence of $E$. coli under poor hygienic conditions.

\section{CONCLUSION}

Besides As contamination in TWs water, fecal contamination in TWs and storage water is a considerable drinking water quality problem in the study area. Arsenic contamination did not show a clear relation to TWs depth, but both shallow and deeper TWs (18$50 \mathrm{~m}$ ) were found to be fecally contaminated in $25 \%$ of the cases. After household water storage - at the point of consumption - an additional estimated $10 \%$ was contaminated; particularly due to poor container placement and sanitation/hygiene practices. Altogether it may be concluded that it is essential to include microbial contamination risks when developing arsenic mitigation strategies.

\section{ACKNOWLEDGEMENTS}

This study supported by DELTAP project funded by NWO-WOTRO research grant. We thank students from AN College, Patna, Prof. Ashok Ghosh and his team for their help during intensive fieldwork.

\section{REFERENCES}

AKVO 2017. https://akvo.org/ (accessed on 30th November 2017).

Embrey, S.S. \& Runkle, D.L. 2006. Microbial quality of the nation's ground-water resources, 1993-2004. Scientific Investigations Report 2006-5290, U.S. Geological Survey, Reston, VA, USA

Leber, J., Rahman, M.M., Ahmed, K.M., Mailloux, B. \& van Geen, A. 2011. Contrasting influence of geology on E. coli and arsenic levels in sedimentary aquifers. Groundwater 49(1): 111-123.

Sommer B., Marino, A., Solarte, Y., Salas, M.L., Dierolf, C., Valiente, C., Mora, D., Rechsteiner, R., Setter, P., Wirojanagud, W., Ajarmeh, H., Al-Hasan, A. \& Wegelin, M. 1997. SODIS: an emerging water treatment process. J. Water SRT-Aqua 46(3): 127-137. 